\title{
Editorial
}

\section{Diabetes patient education: time for a new era}

\section{The aim of patient education}

On one level, diabetes care can be considered as purely involving the control of blood glucose, together with reducing blood pressure, treating hyperlipidaemia and stopping smoking [1]. All these elements may reduce the risk of diabetes-related complications and thus prevent the loss of quality of life. However, most health care professionals consider education in selfmanagement to be an essential part of the approach to managing Type 2 diabetes [2] and many countries are now specifically addressing this. The US government has supported a national diabetes education programme that aims at increasing the proportion of diabetes patients that receive formal diabetes education to $60 \%$ [3]. There has been a plea for a similar response in the UK: 'Considerable energy and resources are required to set up and maintain educational programmes, but the cost per individual is small compared with that of treating the consequences of uncontrolled diabetes' [4]. It is debatable, to what extent this statement is based on fact.

Educational programmes should focus on general knowledge of diabetes, adherence to medication, lifestyle changes and, perhaps, self-monitoring [5]. The goal for educating people with diabetes is to improve their individual self-efficacy and, accordingly, their self-management ability [6]. However, these goals are only tools to achieve outcomes that really matter and as such could be regarded as surrogate end points. Diabetes patient education only makes sense if it succeeds in enabling people with diabetes to (i) improve their glycaemic control, (ii) decrease their modifiable cardiovascular risk factors and (iii) maintain their quality of life. The true challenge of diabetes care is to help patients balance short- and longterm quality of life against the burden of daily intensive selfmanagement [7]. Thus, the elements of diabetes education that really matter are those that are positively related to the outcome measures listed above. The question that needs to be answered is how effective diabetes patient education really is.

\section{The effectiveness of self-management training}

Patient education training programmes are certainly able to increase patients' diabetes-related knowledge. The increase in knowledge is improved by regular reinforcement, but the correlation between increase and better blood glucose regulation is inconsistent. The same applies to other surrogate endpoints: even if they improve after self-management training programmes, their impact on the most relevant outcome measures is weak [8].

Self-management education for adults with Type 2 diabetes improves $\mathrm{HbA}_{1 \mathrm{c}}$ levels at immediate follow-up, and increased contact time increases the effect. The benefit generally declines 1 to 3 months after the end of the intervention, suggesting that learned behaviours lapse over time in the absence of reinforcement. It is noteworthy that few studies have undertaken followup longer than 6 months $[8,9]$. Education may also lead to a fall in participants' body weight, but this also appears to depend on regular contact or reinforcement. The effects of selfmanagement training programmes on lipids and blood pressure have been variable. Studies with positive results have tended to be interactive, individualized and with repetitive interventions. One long-lasting study with a follow-up of 5 years and regular 3-monthly educational sessions found no difference in cardiovascular disease between those who received education and those who did not [10]. The importance of identifying the successful components of an educational intervention is well recognized [7], but few if any robust analyses of the cost-benefit of diabetes education have ever been undertaken [8].

In a randomized controlled trial we studied the effectiveness of an educational programme in 54 Type 2 diabetes patients treated in primary care with maximal dosages of oral hypoglycaemic agents, but whose $\mathrm{HbA}_{1 \mathrm{c}}$ was $\geq 7.0 \%$. Medication was not changed during the intervention period, so we could study the 'educational effect' alone, but it was hard to establish the effects of teaching blood glucose self-monitoring in isolation from the other aspects of the programme [11]. The use of self-monitoring blood glucose (SMBG) in all diabetic patients is widely promoted [12], but its value is still debated [13]. A meta-analysis of randomized trials failed to show any benefit from SMBG in patients with Type 2 diabetes [14]. Moreover, it is suggested daily SMBG in Type 2 diabetes is associated with higher levels of distress, worries and depressive symptoms, because most patients, even those treated with insulin, cannot translate all the information into clear adjustments of their treatments [15]. A systematic review concluded that education, self-management and psychological interventions were unlikely to have a negative impact on psychological well-being or quality of life [16]. However, it is noteworthy that the prevalence of depression decreases linearly with increasing insulin resistance among women without diabetes and then increases among women who have developed the disease, perhaps as a direct result of the diagnosis [17]. Random allocation to more stringent targets has also been associated with a greater perceived burden of treatment and less positive affect in individuals with Type 2 diabetes [18].

The available evidence suggests that diabetes self-management training programmes need to target all the risk factors for both macro- and microvascular disease, as well as providing ongoing educational sessions. 
This view is not new. Ten years ago, De Weerdt et al. concluded that integrating education with other therapies, such as intensified blood glucose lowering therapies, is needed [19]. In 1995, Clement stated that education is most effective when combined with health care provider medication adjustment and reinforcement of educational messages [20]. The importance of medication adjustment is supported by other evidence, suggesting that a target-driven attitude of diabetes care providers may play a pivotal role in achieving the goals of diabetes care $[21,22]$. Perhaps the chances of maintaining patients' quality of life are now much greater than before, not as a result of better patient education, but as a result of the availability of better medication and technology. Certainly patient-centred care alone does not seem to be beneficial in improving biomedical outcomes [23]. In my view, education should primarily focus on what is really effective: improving adherence to medication and, if effective, that would be a step forwards rather than backwards [24].

The difficulty in providing continued and repeated educational sessions can only be solved by integrating diabetes education in daily diabetes care. The literature is divided regarding the relative merits of group vs. individual education [8]. Because individual therapy might be more easily integrated into daily life, self-efficacy is crucial to success, and involving people with diabetes in their own care leads to better results [6], embedded individual diabetes education may have greater potential.

Diabetes education is said to be a cornerstone of modern diabetes treatment. All managed care organizations in the US have made comprehensive changes to their systems to encourage and support better care, including more support for self management by patients [25]. Supporting self-management means the use of effective strategies that include assessment, goal setting, action planning, problem solving and follow-up [26]. Goal setting is related to self-efficacy and should be targeted to realistic goals that really matter. Action planning will not be realized if the support strategies are expensive and burdensome for patients or health care professionals. Problem solving primarily needs mutual understanding with our patients about the origin of the problems in achieving the goals that doctors, diabetes nurses and dieticians propose. If health care providers set demanding targets, which often require major changes in patient's lifestyle, they may cause problems that did not exist before diagnosis. Diabetes education should take the shortest and simplest way to achieve what is feasible and of importance. Effective diabetes self-management programmes must be non-complex, individualized to a person's lifestyle, reinforced over time and respect an individual's habits [27]. They should focus on medication adherence and be cheap and practical. Only those behavioural interventions aimed at improving lifestyle habits that prove effective alongside intensive pharmacological treatment should be promoted. Studies in this field are already underway in the UK, the Netherlands and Denmark, including the ADDITION study [28]. In rethinking diabetes education, it is time for a new era.

\section{G. Rutten \\ Julius Center for Health Sciences and Primary Care, Department of General Practice, University Medical Center Utrecht, the Netherlands}

\section{References}

1 European Diabetes Policy Group (EDPG). A desktop guide to Type 2 diabetes mellitus. European Diabetes Policy Group 1999. Diabet Med 1999; 16: 716-730.

2 Burgers JS, Bailey JV, Klazinga NS, Van der Bij AK, Grol R, Feder G. Inside guidelines: comparative analysis of recommendations and evidence in diabetes guidelines from 13 countries. Diabetes Care 2002; 25: 1933-1939.

3 United States Department of Health and Human Services PHS. Healthy People 2010. Washington DC: Department of Health and Human Services, 2000.

4 Fox Ch, Kilvert A. Intensive education for lifestyle change in diabetes. Br Med J 2003; 327: 1120-1121.

5 Piette JD, Glasgow RE. Education and home glucose monitoring. In: Gerstein, HC, Haynes, RB, eds. Evidenced-Based Diabetes Care, Vol. 1. Hamilton/London: BC Decker, 2001: 207-251.

6 Krichbaum K, Aarestad V, Buethe M. Exploring the connection between self-efficay and effective diabetes self-management. Diabetes Educ 2003; 29: 653-662.

7 Snoek FJ, Visser A. Diabetes education and quality of life. Pat Educ Couns 2003; 51: 1-3.

8 Norris SL, Engelgau MM, Venkat Narayan KM. Effectiveness of selfmanagement training in Type 2 diabetes. Diabetes Care 2001; 24 : 561-587.

9 Norris SL, Lau J, Smith SJ, Schmid CH, Engelgau MM. Self-management education for adults with Type 2 diabetes. Diabetes Care 2002; 25 : 1159-1171.

10 Hanefeld M, Fischer S, Schmechel H, Rothe G, Schulze J, Dude H et al. Diabetes intervention study: multi-intervention trial in newly diagnosed NIDDM. Diabetes Care 1991; 14: 308-317.

11 Goudswaard AN, Stolk RP, Zuithoff NPA, de Valk HW, Rutten GEHM. Long-term effects of self-management education for patients with Type 2 diabetes taking maximal oral hypoglycaemic therapy: a randomized trial in primary care. Diabet Med 2004; 21: 491-496.

12 Amercian Diabetes Association (ADA). Tests of glycemia in diabetes. Diabetes Care 2002; 25: S97-99.

13 Kennedy L. Self-monitoring of blood glucose in type 2 diabetes: time for evidence of efficacy. Diabetes Care 2001; 24: 977-978.

14 Coster S, Gulliford MC, Seed PT, Powrie JK, Swaminathan R. Selfmonitoring in Type 2 diabetes mellitus: a meta-analysis. Diabet Med 2000; 17: 755-761.

15 Franciosi M, Pellegrini F, De Berardis G, Belfiglio M, Cavaliere D, Di Nardo B et al. The impact of blood glucose self-monitoring on metabolic control and quality of life in type 2 diabetic patients: an urgent need for better educational strategies. Diabetes Care 2001; 24 : 1870-1877.

16 Steed L, Cooke D, Newman S. A systematic review of psychosocial outcomes following education. Self management and psychological interventions in diabetes mellitus. Pat Educ Couns 2003; 51: 5-15.

17 Lawlor DA, Smith GD, Ebrahim S. Association of insulin resistance with depression: cross sectional findings from the British women's heart and health study. Br Med J 2003; 327: 1383-1384.

18 Van der Does FE, de Neeling JE, Snoek FJ, Grootenhuis PA, Kostense PJ, Bouter LM et al. Randomized study of two different target levels of glycemic control within the acceptable range in type 2 diabetes. Effects on well-being at 1 year. Diabetes Care 1998; 21: 2085-2093.

19 De Weerdt I, Visser A, Kok G, de Weerdt O, van der Veen E. Randomized controlled multicentre evaluation of an education programme for 
insulin-treated diabetic patients: effects on metabolic control, quality of life and costs of therapy. Diabet Med 1991; 8: 338-345.

20 Clement S. Diabetes self-management education. Diabetes Care 1995; 18: 1204-1214.

21 Goudswaard AN, Stolk RP, de Valk HW, Rutten GEHM. Improving glycaemic control in patients with Type 2 diabetes mellitus without insulin. Diabet Med 2003; 20: 540-544.

22 Renders CM, Valk GD, Griffin S, Wagner EH, Eijk JT, Assendelft WJ. Interventions to improve the management of diabetes mellitus in primary care, outpatient and community settings (Cochrane review). In: The Cochrane Library, Issue 1. Oxford: Update Software, 2002.

23 Van Dam HA, van der Horst F, van den Borne B, Ryckman R, Crebolder H. Provider-patient interaction in diabetes care: effects on patient self-care and outcomes: a systematic review. Pat Educ Couns 2003; 51: 17-28.
24 Glasgow RE, Anderson RM. In diabetes care, moving from compliance to adherence is not enough. Something entirely different is needed. Diabetes Care 1999; 22: 2090-2091.

25 Wagner EH. Chronic disease care. Insights from managed care in the United States will help the NHS. Br Med J 2004; 328: 177-178.

26 Lewis R, Dixon J. Rethinking management of chronic diseases. $\mathrm{Br}$ Med J 2004; 328: 220-222.

27 Anderson L. Health care communication and selected psychosocial correlates of adherence in diabetes management. Diabetes Care 1990; 13: 66-77.

28 Lauritzen T, Griffin S, Borch-Johnsen K, Warham NJ, Wolffenbuttel BHR, Rutten G. The ADDITION study: proposed trial of the costeffectiveness of an intensive multifactorial intervention on morbidity and mortality among people with Type 2 diabetes detected by screening. Int J Obes Relat Metabol Disord 2000; 24: S6-11. 